\title{
Consumo e atitude dos turistas com relação aos produtos gastronômicos do Litoral Paranaense
}

\author{
Consumption and attitude of tourists in relation to gastronomic products of Paraná's Coast
}

\author{
Marcelo Varenhold \\ Chayenne Aparecida Goes \\ Mirna de Lima Medeiros
}

Universidade Estadual de Ponta Grossa - Ponta Grossa - Paraná - Brasil

\begin{abstract}
Resumo: Elementos gastronômicos locais podem expressar contextos (econômicos, históricos, culturais e ambientais) particulares. Seu consumo no turismo pode ser o auge de uma experiência turística ou um serviço de apoio ao consumidor, dependendo de circunstâncias específicas. É importante, portanto, entender o comportamento do turista com relação aos elementos existentes para que se possa pensar alternativas no sentido de incrementar a sua experiência. $O$ presente trabalho teve como objetivo analisar o consumo e as atitudes dos turistas com relação aos produtos gastronômicos do Litoral paranaense. Para isto houve estudo bibliográfico sobre os temas de indicação geográfica e turismo gastronômico; análise documental e, por fim, a aplicação de questionário online aos visitantes do Litoral paranaense (obtendo total de 188 respostas). Após análise dos dados, se verificou que a região litorânea do Paraná possui alguns produtos considerados "do litoral", entre os quais quatro com processos de indicação geográfica em andamento (Cachaça, Farinha de Mandioca, Bala de Banana e Serviço Gastronômico do Barreado). O turista consome diversos dos produtos e àqueles que possuem pleito de IG se destacam nesse quesito. Além disso a região tem potencial para o turismo gastronômico e foi possível verificar que algumas atividades já são desenvolvidas, mas outras ainda podem ser operacionalizadas. Isso porque foi percebida atitude favorável com relação a essas.
\end{abstract}

Palavras-chave: Turismo Gastronômico. Indicação Geográfica. Litoral Paranaense.

Abstract: Local gastronomic elements can express particular contexts (economic, historical, cultural and environmental). The consumption in tourism can be the peak of a tourist experience or a customer service depending on specific circumstances. It is important, therefore, to understand the behavior of the tourist in relation to the existing elements so that one can think of alternatives in order to increase their experience. The present work had as objective to analyze the consumption and the attitudes of the tourists in relation to the gastronomic products of the coast of Parana. For this, there was a bibliographical study on the subjects of geographical indication and gastronomic tourism; document analysis and, finally, the application of an online questionnaire to visitors from the coast of Paraná (obtaining 188 responses). After analyzing the data, we verified that the coastal region of Paraná has some products considered "coastal", including four with processes of geographic indication in progress. In addition, the region has potential for food tourism and it was possible to verify that some activities are already developed, but others can still be operationalized. This is because a favorable attitude has been perceived in relation to these.

Key words: Food Tourism. Geographical Indication. Paraná Coastal Region. 


\section{Introdução}

Os serviços de alimentação são fundamentais para o turismo devido à necessidade básica de nutrição do ser humano. Porém, segundo Gândara et. al (2009, p.179-180), "é imprescindível pensar a comida não apenas como fonte de saciação de necessidades fisiológicas, mas também de necessidades sociais e psicológicas". Além disso, a alimentação tem potencial turístico quando se trabalha suas características culturais ou até diferenças como temáticas, inovações, entre outros (FAGLIARI, 2005; GIMENES-MINASSE, 2015). Desse modo torna-se interessante aos turistas e pode ser utilizada enquanto fator de atração e promoção de um local, bem como fator de fortalecimento de uma identidade particular, de geração de renda e até desenvolvimento territorial (KIVELA; CROTTS, 2006; LIN; PEARSON; CAI, 2011).

Assim, alguns destinos passam a ser conhecidos (ou mais conhecidos) por sua oferta gastronômica. No Paraná, conforme a Secretaria de Esporte e Turismo (2017), dentre as regiões turísticas, "Campos Gerais", "Cataratas do Iguaçu e Caminhos do Lago", "Corredores das Águas", "Litoral”, "Riquezas do Oeste", e "Rotas do Iguaçu" possuem o turismo gastronômico como um dos seus principais segmentos. Dentre essas escolheu-se o Litoral para estudo tendo em vista a variedade de produtos gastronômicos, bem como a presença de produtos pleiteantes de indicação geográfica (que notoriamente tem vínculo com o território).

A indicação geográfica (INPI, 2018) "é usada para identificar a origem de produtos ou serviços quando o local tenha se tornado conhecido ou quando determinada característica ou qualidade do produto ou serviço se deve a sua origem". As IGs são signos distintivos particularmente interessantes ao turismo, especificamente no segmento gastronômico. O nome geográfico reconhecido ao mesmo tempo que passa a identificar o produto, também termina por promover o local que possui esse nome. Por outro lado, o desenvolvimento de ações e atividades turísticas relacionadas ao produto com IG podem aumentar a sua valorização. Desse modo, nessa intersecção, há benefício em ambas as áreas.

Tendo em vista o panorama apresentado, indagou-se: Qual a relação do turista-consumidor com os produtos gastronômicos do litoral do Paraná? E, mais especificamente, com aqueles que pleiteiam indicação geográfica? Diante dessa indagação, delineou-se como objetivo geral: Analisar o consumo e as atitudes dos turistas com relação aos produtos gastronômicos do litoral Paranaense. Para seu alcance propôs-se os seguintes objetivos específicos: Entender a relação entre turismo e indicação geográfica; descrever os pedidos de indicação geográfica do Litoral do Paraná e verificar as ações de consumo e interesse dos turistas com relação aos produtos gastronômicos do Litoral do Paraná.

Fagliari (2005) menciona que é preciso compreender o perfil do turista para então trabalhar os elementos gastronômicos. Assim a pesquisa torna-se relevante ao mercado. Também possui implicações acadêmicas ao ampliar as discussões relativas ao turismo, comportamento do consumidor e indicações geográficas.

Após a presente introdução, há uma exposição teórica com relação ao turismo gastronômico e indicação geográfica. Em seguida são expostas as escolhas metodológicas. Com base nestas os resultados e discussões do trabalho são apresentados. Por fim, são colocadas algumas considerações e apresentadas as referências utilizadas.

\section{Turismo, Gastronomia e Indicações Geográficas}

A comida é mais do que uma fonte essencial de nutrientes, é também uma componente chave da cultura, fundamental para o senso de identidade. Através da alimentação um grupo pode se distinguir dos demais, reconhece-se e por isso é reconhecido, a partir de cada especificidade, tanto em relação ao uso de ingredientes específicos quanto aos hábitos alimentares, formas de preparo e consumo (FRANZONI, 2016; TONINI, 2013). 
Decorrente desses fatores, já se reconhece que a comida para além de sanar uma necessidade fisiológica, pode configurar-se como diferencial e até motivação para o deslocamento, faz parte da imagem de destinos turísticos e representa uma fatia significativa dos gastos em viagem (ALTINTZOGLOU; HEIDE; BORCH, 2016). "As práticas alimentares tradicionais, seus produtos e seus serviços, ao serem incorporados no contexto turístico, tornam-se - mais do que manifestações culturais e identitárias elementos estratégicos para a criação de uma "marca" local" (GIMENES-MINASSE, 2015, p.190).

Karim e Chi (2010) mencionam que existe viajantes que buscam comida similar à de casa em uma viagem, mas também como parte da viagem, a alimentação pode se tornar um atrativo devido à carga cultural e experiência que está pode transmitir. Sendo assim, Quan e Wang (2004) defendem que produtos gastronômicos diferentes dos encontrados na rotina do dia a dia, tornam-se motivações principais de uma visita a um restaurante ou destino.

Quando se torna motivação principal de viagem tem-se o turismo gastronômico que é:

Segmento turístico emergente capaz de posicionar destinos no mercado turístico, quando utilizado como elemento para a vivência da experiência da cultura local pelo turista por meio da culinária típica. A oferta turística de serviços de alimentação, item que faz parte da estada do turista, apresenta-se, portanto, como uma vantagem competitiva no desenvolvimento do turismo de uma localidade, podendo ser utilizada como um diferencial passível de proporcionar experiências únicas para o turista, e assim tornar-se também um diferencial para sua comercialização (MINISTÉRIO DO TURISMO, 2010, p.25).

Gândara et. al. (2009, p.181) apontam ainda que o turismo gastronômico pode ser operacionalizado a partir de atrativos principais ou secundários de uma viagem. São exemplos: bares e restaurantes, pratos e produtos típicos, visitas a local de produção, degustação, lojas e mercados, eventos, rotas gastronômicas, escolas e oficinas de gastronomia, museu, meio de transporte, livros de receitas, entre outros (FAGLIARI, 2005; GIMENES-MINASSE, 2015; HENDERSON, 2009).
No momento do consumo do produto turístico gastronômico, os turistas buscam por experiências memoráveis (STONE, MIGCZ, WOLF, 2018). Os elementos gastronômicos podem ser trabalhados de diferentes maneiras, e de acordo com Fagliari (2005, p.41) "quanto maior seu caráter diferencial, mais interessante será aos olhos do turista" tornando assim um atrativo turístico passível de comercialização.

Além do momento anterior relativo às expectativas, do momento durante a visita com atividades gastronômicas, um terceiro momento pode ser trabalhado relativo à pós-viagem. Os souvenirs e os livros de receitas podem servir como instrumento para prolongar a experiência turística (HENDERSON, 2009; ALTINTZOGLOU; HEIDE; BORCH, 2016). Há, portanto, diversos momentos nos quais pode-se trabalhar com os elementos gastronômicos.

Ribeiro-Martins e Silveira Martins (2018, p.187) ressaltam que "o turismo gastronômico surge não apenas como uma atividade econômica autônoma, mas também como um catalisador do desenvolvimento e crescimento regional". Por este se complementar e se apoiar em diferentes setores como o a agricultura e economia local, pode ser atrelado a indicação geográfica, quando se vale desse diferencial.

A Indicação Geográfica (IG) "é usada para identificar a origem de produtos ou serviços quando o local tenha se tornado conhecido ou quando determinada característica ou qualidade do produto ou serviço se deve a sua origem" (INPI, 2018). No Brasil possui duas tipologias: indicação de procedência (IP) que "refere-se ao nome do local que se tornou conhecido por produzir, extrair ou fabricar determinado produto ou prestar determinado serviço"; e denominação de origem (DO) que "refere-se ao nome do local, que passou a designar produtos ou serviços, cujas qualidades ou características podem ser atribuídas a sua origem geográfica".

Alguns lugares tornam-se notórios (ou mais notórios) devido à sua produção (artesanal, manufatureira, de serviços, etc.). Pode-se verificar que diversos locais pelo mundo buscam uma valorização 
de seus produtos utilizando-se de indicações geográficas. Esse é o caso da região de Champagne Ardenne, na França. No Brasil o primeiro registro desse tipo foi conferido aos vinhos do Vale dos Vinhedos, no Rio Grande do Sul. No país existem, até o presente (última busca: 27 novembro de 2018), 61 IGs reconhecidas e 96 processos em andamento, havendo predominância da categoria IP (Tabela 01).

Tabela 01: Números de pedidos concedidos e em andamento de IG no Brasil e Paraná

\begin{tabular}{|c|c|c|c|c|}
\hline \multicolumn{2}{|c|}{$\begin{array}{c}\text { Números de pedidos concedidos e em andamento } \\
\text { de Indicação Geográfica }\end{array}$} \\
\hline Categorias & \multicolumn{2}{|c|}{ Reconhecidas } & \multicolumn{2}{|c|}{$\begin{array}{c}\text { Em } \\
\text { andamento }\end{array}$} \\
\cline { 2 - 5 } & Brasil & Paraná & Brasil & Paraná \\
\hline $\begin{array}{c}\text { Denominação de } \\
\text { Origem (DO) }\end{array}$ & 11 & 1 & 20 & 1 \\
\hline $\begin{array}{c}\text { Indicação de } \\
\text { Procedência (IP) }\end{array}$ & 50 & 6 & 76 & 10 \\
\hline
\end{tabular}

Fonte: INPI, 2018.

Cerdan (2013, p.131) defende que quando uma região obtém reconhecimento de IG essa pode "induzir a abertura e o fortalecimento de atividades e de serviços complementares, relacionados à valorização do patrimônio, à diversificação da oferta, às atividades turísticas [...] ampliando o número de beneficiários". Segundo Nunes, Bandeira e Nascimento (2012, p. 344) "as IGs são ferramentas estratégicas para a ampliação da competitividade dos pequenos negócios e para a região onde estão instalados".

A utilização de signos distintivos como estes, age de forma benéfica sobre os produtos ou serviços registrados. Pellin e Curadi (2018) defendem que as IGs "podem ser consideradas estratégias de desenvolvimento territorial sustentável em função de estimularem várias dimensões do desenvolvimento" em diferentes dimensões: econômica, social, ambiental e cultural. As IGs servem como meio de preservação do patrimônio cultural e imaterial (NASCIMENTO; NUNES; BANDEIRA, 2012) ao mesmo tempo que incrementam a renda através destes produtos (VARELLA; BARROS, 2005).

Diante das vantagens apontadas, o turismo pode ser incrementado e valorizado com estes produtos detentores de registro. Pode haver uma utilização e consumo turístico antes, durante e depois da visita, como se pode observar no quadro 01:

Quadro 01: Possibilidades de interseção entre Indicações Geográficas e Turismo

\begin{tabular}{|c|c|c|}
\hline Antes da Visita & Durante a Visita & $\begin{array}{c}\text { Pós- } \\
\text { Visitação }\end{array}$ \\
\hline 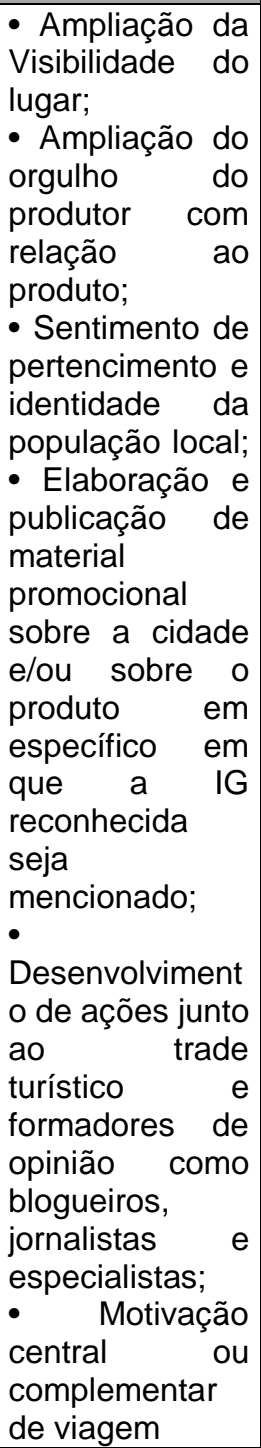 & $\begin{array}{l}\text { - Adição de valor } \\
\text { simbólico/intangív } \\
\text { el } \\
\text { ao produto com } \\
\text { IG; } \\
\text { - Desenvolvimento } \\
\text { de atividades } \\
\text { relacionadas ao } \\
\text { bem ou serviço } \\
\text { registrado com IG: } \\
\text { eventos sazonais; } \\
\text { rotas temáticas; } \\
\text { degustações; } \\
\text { harmonizações; } \\
\text { abertura dos } \\
\text { locais de à } \\
\text { fabricação or a de } \\
\text { visitação; ofertas } \\
\text { de cursos, etc.; } \\
\text { - Desenvolvimento } \\
\text { de atividades de } \\
\text { apoio turístico } \\
\text { (que possibilitam a } \\
\text { estadia do turista) } \\
\text { como hotelaria; } \\
\text { restauração; } \\
\text { artesanato; entre } \\
\text { outros serviços; } \\
\text { - Construção de } \\
\text { equipamentos e } \\
\text { facilidades para } \\
\text { uso turístico e } \\
\text { também de sua } \\
\text { população. }\end{array}$ & $\begin{array}{l}\text { - Consumo do } \\
\text { produto como } \\
\text { souvenir de } \\
\text { viagem pelo } \\
\text { turista; } \\
\text { - O produto } \\
\text { com IG dado } \\
\text { de presente a } \\
\text { terceiros } \\
\text { pode se } \\
\text { configurar } \\
\text { como uma } \\
\text { forma de } \\
\text { informação } \\
\text { sobre um } \\
\text { atributo de } \\
\text { um destino e } \\
\text { até motivar a } \\
\text { visita de um } \\
\text { terceiro. }\end{array}$ \\
\hline
\end{tabular}

Fonte: Medeiros e Passador (2015, p. 72).

Com essa possibilidade de interseção do turismo com as indicações geográficas, se faz necessário essa valorização. Segundo Oliveira e Oliveira (2013, p.10) a indicação geográfica pode ser um produto que deriva de uma construção cultural de um local, sendo assim um atrativo que pode ser preservado com o turismo e a indicação geográfica. 


\section{Metodologia}

A pesquisa se caracteriza como exploratória e descritiva. Para a consecução do objetivo de analisar o consumo e as atitudes dos turistas com relação aos produtos gastronômicos do Litoral Paranaense foram estabelecidos os meios de coleta de dados: análise documental e aplicação de questionário aos turistas.

A pesquisa documental teve como foco identificar produtos alimentares ofertados na região e quais pleiteiam indicação geográfica na região estudada. Teve como base de dados do INPI (Instituto Nacional da Propriedade Industrial), do SEBRAE (Serviço Brasileiro de Apoio às Micro e Pequenas Empresas) e IBGE (Instituto Brasileiro de Geografia Estatística). Foram listados nove produtos "do litoral". Esses nove foram listados em uma etapa inicial do questionário, mas optou-se pelo aprofundamento da relação de consumo com relação a um menor número de objetos devido à extensão que o instrumento de pesquisa tomaria. Assim, o critério de estar pleiteando IG foi o utilizado e, dentre os nove, foram selecionados quatro: 03 produtos e 01 serviço gastronômico. São eles: Bala de Banana; Serviço Gastronômico do Barreado; Farinha de Mandioca e Cachaça (sua abrangência e características constam na seção de resultados).

O questionário estruturado teve como públicoalvo os turistas que já estiveram em pelo menos em um município da região litorânea paranaense. Sua aplicação foi online (baseado no Google Docs) e foi divulgado em redes sociais (Facebook), com postagens regulares semanais visando coletar o máximo de respostas possível. Brickman-Bhutta (2009, p. 4 apud BALTAR, BRUNET, 2011 p. 65, tradução nossa) defende que o Facebook e outras redes sociais têm o poder de divulgação e propagação eficiente, que fora dos meios sociais exigiria uma equipe grande e com custos de impressão altos. $\mathrm{Na}$ presente pesquisa, o compartilhamento inicial ocorreu via redes sociais dos pesquisadores com convite para re-compartilhamento e para que aqueles que atendiam ao critério respondessem ao questionário. Com isto o compartilhamento deste se deu também por pessoas e entidades relacionadas com o meio acadêmico, com o Turismo no Litoral, bem como com o pleito de indicação geográfica. O período de aplicação foi de 45 dias (21 de maio a 05 de julho de 2018). Obteve-se um total 188 respondentes.

O processo de análise dos dados seguiu os preceitos de Bardin (1977) com a "pré analise" buscando formar uma organização coerente para o trabalho, juntamente com definições de linhas e métodos de pesquisa. O segundo, a "exploração do material" buscando um aprofundamento e entendimento no assunto e dessa maneira chegar resultados preliminares. Por fim, terceira etapa tange ao "tratamento dos resultados e interpretação dos dados obtidos" através de uma análise sucinta destes dados.

\section{Resultados e Discussões}

O Litoral Paranaense, ou Microrregião de Paranaguá, possui uma faixa territorial de cerca de 98 Km de extensão. Abriga os municípios de Guaratuba, Matinhos, Pontal do Paraná, Paranaguá, Morretes, Antonina e Guaraqueçaba e é uma região próxima à capital do estado (Curitiba) como pode-se observar no Mapa 01.

Mapa 01: Localização dos municípios do Litoral Paranaense

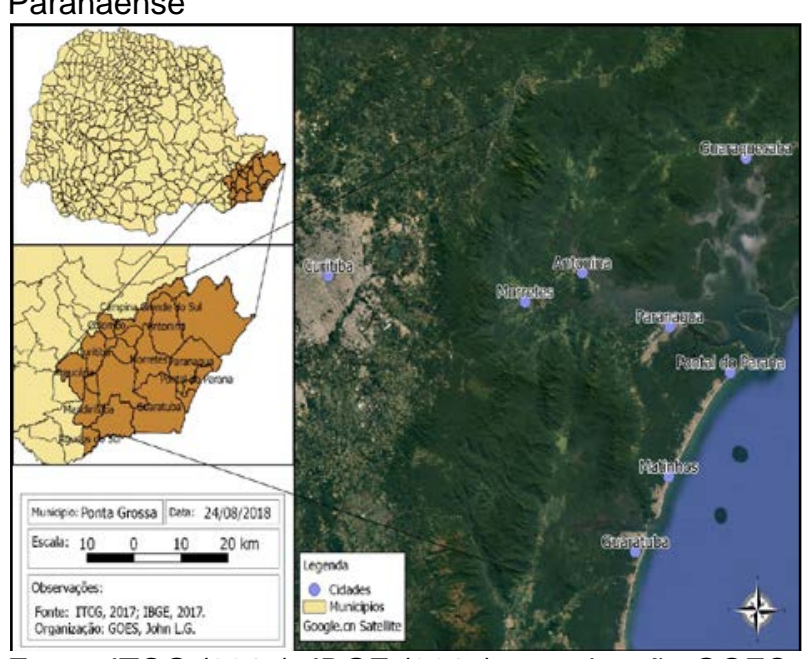

Fonte: ITCG (2017), IBGE (2017) organização GOES, John L.G (2018).

O critério de seleção dos respondentes para o instrumento de pesquisa proposto, foi que o sujeito já tivesse visitado pelo menos um dos municípios supramencionados ao menos uma vez, independentemente das suas motivações. Foram obtidas 188 respostas válidas em uma amostra 
composta por pessoas residentes em 37 municípios diferentes, com idades de 16 a 71 anos, de ambos os sexos.

Como o foco da pesquisa era o consumo e atitude com relação aos produtos gastronômicos do Litoral. A primeira parte do questionário era mais ampla e contemplava os principais produtos considerados "típicos" dos diferentes municípios do litoral paranaense. A tabela 01 expõe o consumo desses produtos por parte dos turistas respondentes. em andamento (início do processo: 2015). Todos são na categoria de indicação de procedência(quando o local se torna conhecido pela produção ou realização de um serviço) e foram solicitados pela mesma instituição (ADETUR Litoral).

A ADETUR Litoral (Agência de Desenvolvimento do Turismo Sustentável) atua "como agência de desenvolvimento e órgão gestor e de apoio aos projetos e iniciativas relacionadas ao turismo" (ADETUR Litoral, s/d). A agência de desenvolvimento atua nas comunidades locais,

Tabela 01: Número de menções com relação ao consumo do turista na região estudada

\begin{tabular}{|c|c|c|c|c|c|}
\hline Produtos & $\begin{array}{c}\text { Já comprei, } \\
\text { compraria } \\
\text { novamente }\end{array}$ & $\begin{array}{c}\text { Já comprei, } \\
\text { não } \\
\text { compraria } \\
\text { novamente }\end{array}$ & $\begin{array}{c}\text { Nunca } \\
\text { comprei, } \\
\text { tenho } \\
\text { interesse em } \\
\text { comprar }\end{array}$ & $\begin{array}{c}\text { Nunca } \\
\text { comprei, não } \\
\text { tenho } \\
\text { interesse em } \\
\text { comprar }\end{array}$ & $\begin{array}{c}\text { Não sei } \\
\text { opinar }\end{array}$ \\
\hline Bala de Banana & 146 & 7 & 17 & 17 & 1 \\
\hline Cachaça de Cataia & 44 & 7 & 83 & 38 & 16 \\
\hline Cachaça de Morretes & $\mathbf{6 2}$ & $\mathbf{8}$ & $\mathbf{7 5}$ & $\mathbf{3 1}$ & $\mathbf{1 2}$ \\
\hline Camarão & 126 & 4 & 27 & 29 & 2 \\
\hline Farinha de Mandioca & $\mathbf{9 4}$ & $\mathbf{2}$ & $\mathbf{6 9}$ & $\mathbf{1 1}$ & 12 \\
\hline Ostras & 53 & 17 & 41 & 65 & 12 \\
\hline Pratos de Tainha & 55 & 13 & 59 & 41 & 20 \\
\hline Barreado & 123 & 14 & 36 & 9 & $\mathbf{6}$ \\
\hline Siri & 83 & 9 & 42 & 44 & 10 \\
\hline
\end{tabular}

Fonte: Dados da pesquisa, 2018. (Grifo nosso)

Os produtos listados são encontrados no Litoral, sendo consumidos em restaurantes, hotéis, e também como souvenir gastronômico. A partir da tabela 01 se pode observar que os produtos que 0 consumo dos produtos pleiteantes de indicação geográfica se destaca (cachaça, farinha de mandioca, bala de banana e barreado). Esses também se destacam em termos de intenção de recompra. Nesse sentido, a escolha pelo aprofundamento das ações e interesses do turista com relação a esses quatro produtos pareceu acertada.

Antes de detalhar essas questões é interessante, portanto, caracterizar esses produtos e o processo em andamento. Por meio de análise documental na base de dados odo INPI foi verificada a existência de quatro pedidos de indicação geográfica auxiliando no desenvolvimento, promovendo, divulgando e enaltecendo o turismo na região, além da promoção de eventos proporcionando maior visibilidade da região e dos produtos que esta oferece. Seu site institucional possibilita também obter informações sobre os locais nos quais a agencia atua. Com abas separadas por municípios é possível obter informações sobre os municípios, vias de acesso, atrativos, serviços, alimentação e hospedagem. Auxiliando o turista e divulgando os empreendimentos da região.

Para a valorização dos produtos da região, e estimulados por entidades como SEBRAE e Ministério da Agricultura, Pecuária e Abastecimento (MAPA), os produtores juntamente com a ADETUR Litoral optaram então pela indicação geográfica. Em um primeiro 
momento foram motivados e participaram ativamente 20 produtores/empreendedores de todas as categorias está na área de abrangência de todos os pedidos (04), seguido por Antonina e Guaraqueçaba (03),

Quadro 02: Produtos que pleiteiam Indicação Geográfica no Litoral Paranaense

\begin{tabular}{|c|c|c|c|c|}
\hline \multicolumn{5}{|c|}{ Descrição dos pedidos de Indicações de Procedência no Litoral do Paraná } \\
\hline Tipo de produto & Categoria & Nome Geográfico & Área de Abrangência & Representação Figurativa \\
\hline Cachaça & Produto & Morretes & Morretes & \\
\hline $\begin{array}{l}\text { Farinha de } \\
\text { Mandioca }\end{array}$ & Produto & Litoral do Paraná & $\begin{array}{c}\text { Morretes, Antonina, } \\
\text { Guaraqueçaba, } \\
\text { Paranaguá, Pontal } \\
\text { do Paraná, Matinhos e } \\
\text { Guaratuba }\end{array}$ & \\
\hline Bala de Banana & Produto & Antonina & $\begin{array}{l}\text { Morretes, Antonina e } \\
\text { Guaraqueçaba }\end{array}$ & \\
\hline Barreado & Serviço & Litoral do Paraná & $\begin{array}{c}\text { Morretes, Antonina, } \\
\text { Guaraqueçaba e } \\
\text { Paranaguá }\end{array}$ & \\
\hline
\end{tabular}

Fonte: Elaborado com base em INPI (2018) e SEBRAE (s/d).

(Cachaça: 03; Farinha de Mandioca: 04; Bala de Banana: 02 e Barreado: 11). A agência pleiteia os pedidos de IG junto ao INPI devido ao fato de ser ligada ao comércio e produtores, contudo o INPI questionou a sua representatividade com relação aos produtores. Esse fato é uma das causas para ainda não ter havido o reconhecimento das IPs em questão.

Os quatro pedidos encontram-se com situações diferentes, pois as análises são feitas em separado. Constam como: pedido depositado, em análise ou com pedidos de alterações. O quadro 02 apresenta dados dos pedidos, com tipo de produto, a categoria de produto, o nome geográfico, a área de abrangência proposta para delimitação da IG e sua representação figurativa.

As delimitações propostas são de relevância, pois após o reconhecimento de uma IG apenas os produtores que estão inseridos na área especificada, que produzem 0 item em conformidade com o regulamento de uso registrado, podem utilizar a indicação geográfica. Pode-se observar que Morretes
Paranaguá (02) pedidos e Pontal do Paraná, Matinhos e Guaratuba (01).

Os produtos listados possuem características marcantes da região, os quais são expressos nas representações figurativas. A proposta de representação da bala de banana Antonina possui, em sua borda, um disco com quadrados como há em um equipamento utilizado no processo de separação e embalagem da bala (e também lembra a bala em si que é comercializada na forma quadrada e tem tonalidade escura). Também se valem de ilustrações relacionadas com instrumentos de preparo as representações do serviço gastronômico do barreado (panela de barro) e a cachaça (alambique).

Pode-se perceber, decorrente do próprio pleiteante e também das menções dos respondentes da pesquisa. Que esses quatro itens gastronômicos podem ser aproveitados turisticamente na região. Assim, foi 
analisado, além do consumo, o conhecimento com relação aos produtos/serviço pleiteantes de indicação geográfica (Tabela 02).

Pode-se observar que dos quatro itens, o produto mais consumido pelos respondentes durante a viagem foi o serviço gastronômico do barreado (103 respostas). Em seguida, com quase metade dos respondentes, houve o consumo da bala de banana (82 respostas). Os menos consumidos no local foram a cachaça (23 respostas) e a farinha de mandioca (36 respostas). $O$ produto que obteve destaque nas compras para presentear alguém, ainda que com poucas menções (22),foi a cachaça de Morretes. Já os produtos comprados para consumo próprio com maior incidência foram a farinha (55) e a bala de banana (41). Esse fato pode ter relação com a adequação dos produtos como souvenirs gastronômicos que podem ter vários aspectos desenvolvidos conforme analisado expostas na listagem foram compiladas a partir do referencial teórico relacionado ao uso de elementos gastronômicos como atrativo turístico (FAGLIARI, 2005; GÂNDARA et. al., 2009; GIMENES-MINASSE, 2015; entre outros) e os respondentes possuíam como opção: sim; talvez e não. A atitude predominante (favorável, neutra ou desfavorável) é exposta no quadro 03 , conforme percentual predominante de respondentes:

A partir dos dados expostos fica perceptível a atitude favorável dos turistas com relação a quase todas as atividades relacionadas aos produtos gastronômicos listadas. Em quase todos os casos mais da metade dos respondentes (ou percentual próximo da metade) gostaria de realizar as atividades. Isso só não se confirmou com relação à eleição de representantes (rei, rainha, mascote, etc.), e pode ser um aspecto mais valorizado pelos produtores ou pela

Quadro 03: Predominância de interesse dos turistas com relação às atividades gastronômicas:

\begin{tabular}{|c|c|c|c|c|}
\hline Atividades & Cachaça & Farinha & Bala de Banana & Barreado \\
\hline Festival Gastronômico & $63 \%$ & $48 \%$ & $52 \%$ & $75 \%$ \\
\hline Eleição de representantes & $36 \%$ & $40 \%$ & $40 \%$ & $38 \%$ \\
\hline Degustação & $81 \%$ & $71 \%$ & $79 \%$ & $85 \%$ \\
\hline Melhores produtos da região & $79 \%$ & $75 \%$ & $80 \%$ & $88 \%$ \\
\hline Visita a produção & $44 \%$ & $35 \%$ & $47 \%$ & $46 \%$ \\
\hline Oficina & $74 \%$ & $69 \%$ & $68 \%$ & $73 \%$ \\
\hline Museu & $80 \%$ & $74 \%$ & $80 \%$ & $77 \%$ \\
\hline \multirow{2}{*}{ Legenda: } & Gostaria de realizar a atividade relacionada ao produto \\
\cline { 2 - 5 } & \multicolumn{2}{|l|}{ Talvez realizasse a atividade relacionada ao produto } \\
\cline { 2 - 5 } & \multicolumn{2}{l}{ Não gostaria da atividade relacionada ao produto } \\
\hline
\end{tabular}

Fonte: Dados da pesquisa, 2018.

por Kovaleski (2017).

Os produtos menos consumidos podem estar relacionados com o contato com esses produtos, pois um percentual significativo dos respondentes do questionário mencionou que não tiveram contato com esses. Ainda assim, vários apontaram que possuem interesse de compra pelos produtos nunca antes consumidos (Cachaça: 66 e Farinha: 53).

Foi indagado se os turistas teriam interesse em realizar atividades relacionadas aos produtos gastronômicos caso fossem ofertadas. As atividades população local (contudo isso necessitaria de outra pesquisa para verificação). Houve variação pequena com relação aos produtos, mas de uma forma geral pode-se considerar que houve certo equilíbrio de acordo com a atividade.

O mercado de eventos mostra-se um ramo convincente para investimentos, pois, além do demonstrado interesse dos turistas (maioria dos respondentes), segundo Fagliari (2005, p.62) "os eventos constituem-se no elemento mais utilizado para a criação de atrativos gastronômicos. [...] As 
localidades os aproveitam das mais diversas formas e os criam dependendo da potencialidade da região ou mesmo de uma oportunidade de mercado". Além disso, segundo a autora, eventos gastronômicos podem ser promovidos por diferentes entidades (públicas ou privadas) incluindo associações ou entidades de classe. Com isso iniciativas podem ser tomadas pelos empreendedores ou pelas organizações ligadas aos produtos ou à temática de indicações geográficas, como ADETUR Litoral e SEBRAE.

Na região já é possível encontrar eventos ligados a gastronomia como o Fórum Tutano Gastronomia e o Sabores do Litoral, os quais são oportunidades para combinar os produtos pleiteantes de registro de indicação geográfica. Outro evento recente que foi encontrado na região foi o II Encontro de Negócios para Indicações Geográficas do Litoral, em que ocorreu a participação dos empreendedores locais.

O uso das indicações geográficas em eventos possui diferentes públicos. Houve um evento destinado aos produtores e acadêmicos unindo seminários, cursos, palestras, entre outras atividades ligadas à área; e, em outro momento, em os produtos com pleito de IG foram destacados em eventos tradicionais. Ainda que nem todos sejam destinados aos turistas, os eventos auxiliam a divulgação dos produtos e disseminação de conhecimento relacionado ao signo distintivo. A partir do momento que as pessoas entendem o que é uma indicação geográfica, torna-se possível valoriza-la.

Dentro de eventos gastronômicos, ou de forma separada, podem ocorrer ainda outras atividades que unem produtos pleiteantes de IG com o turista, como a degustação, harmonização e eleição dos melhores produtos da mesma tipologia de IG. Pode também haver o uso de brindes como copos e livros de receita para prolongar a experiência do turista. (FAGLIARI, 2005; HENDERSON, 2009). Os respondentes em questão mostraram-se favoráveis a quase todas essas atividades como mencionado anteriormente.
Outra questão indagada aos turistas foi relacionada à visitação no local de produção. Essa atividade, em geral, permite ao turista compreender os processos produtivos. Além disso, também há possibilidade de realização de atividades combinadas como degustações, que possibilitam ao turista/consumidor provar qual versão dos produtos mais Ihe agrada; e oficinas e cursos acerca do produto.

Segundo Sharples (2003) viajantes podem unir as viagens com cursos gastronômicos. Estas atividades dão ao público uma abertura para entender (e vivenciar) o processo de preparação dos produtos, possibilitando assim a inserção de elementos culturais e históricos. Outra atividade que pode ser aproveitado pelos espaços de produção no momento de tours pelo empreendimento e a consolidação de um espaço (loja) para comercialização. Esses, conforme Fagliari (2005), podem fazer parte de um roteiro turístico do município.

Museus ou espaços de memória podem servir de instrumento para transmitir e preservar a história e cultura de um local, bem como informar com relação às evoluções no processo de produção e até com relação ao que é indicação geográfica. Houve atitude positiva dos turistas com relação a esse aspecto, entretanto cabe destacar que o sucesso nesse tipo de atividade depende muito da curadoria, formatação, interatividade entre outros fatores.

Um ponto não questionado durante a pesquisa, porém que pode ser desenvolvido na região é a criação de uma rota gastronômica e utilização de meios de transporte mesclado com uso de elementos gastronômicos. Segundo Fagliari (2005, p.64) "as rotas gastronômicas constituem um elemento bastante utilizado por alguns países como atrativo turístico", sendo assim estes são formados por "itinerários que englobam diversos atrativos e são desenvolvidos e promovidos a partir da parceria entre órgãos públicos, associações, proprietários de atrativos e produtores, entre outros", tornando assim uma parte na oferta turística de uma localidade. E ainda podem possuir diferentes âmbitos (municipal, regional e nacional) e consequentemente levam o turista a ter um maior 
tempo de estagia na região além do acréscimo de vendas.

Um dos meios de transportes utilizados como acesso aos municípios do litoral do Paraná é pela estrada férrea com o serviço da Serra Verde Express. A região pode ser articulada para que uma rota gastronômica se desenvolva aliando este potencial turístico (trem), em que atividades (visita a locais de produção, oficinas, cursos, degustações, etc.) poderiam ser desenvolvidas com os turistas após o desembarque, com a cooperação entre os municípios e empreendedores detentores destas futuras indicações geográficas.

O conhecimento e preferência por produtos com indicação geográfica também foram questionados. De acordo com a pesquisa, 48\% (91 respondentes) dos respondentes julgam ter médio conhecimento sobre o tema; 17\% (33 respondentes) julgam ter muito conhecimento. Por fim 35\% (67 respondentes) julgam ter pouco conhecimento ou nenhum conhecimento. Esse conhecimento certamente impacta na preferência por produtos que possuam esse tipo de reconhecimento. Os resultados quais são apresentados a seguir (gráfico 01):

Gráfico 01: Preferência dos turistas respondentes com relação a comprar um produto com IG

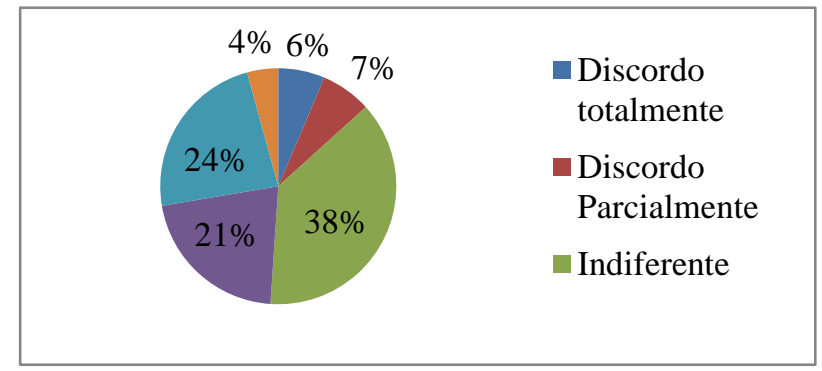

Fonte: Dados da pesquisa, 2018.

A pesquisa mostrou que predominou a concordância total ou parcial (somando 45\%) a respeito da compra por produtos que possuem indicação geográfica. Entendendo que com esse processo ocorre à valorização do produto ou serviço, bem como também da região em que este está localizado. A pesquisa buscou verificar se o fato de possuir IG influenciaria na escolha de destinos. O gráfico 2 ilustra as respostas referentes a essa questão.

Nota-se certo equilíbrio entre a indiferença (28\%), a concordância parcial (27\%) e a concordância total (27\%). Já restante dos respondentes (18\%) discorda totalmente, parcialmente ou não sabe opinar. Esse percentual elevado pode ter relação com a complementação de outras intenções de viagem, pois não foi indagado se apenas a IG motivaria 0 deslocamento. Há indícios, contudo, que locais que possuir IG torna a região valorizada por este aspecto, trazendo assim a possibilidade de trabalhar os produtos turísticos em diferentes âmbitos.

Gráfico 02: Preferência dos respondentes quanto à visitação de um destino se soubesse que ele possui uma IG

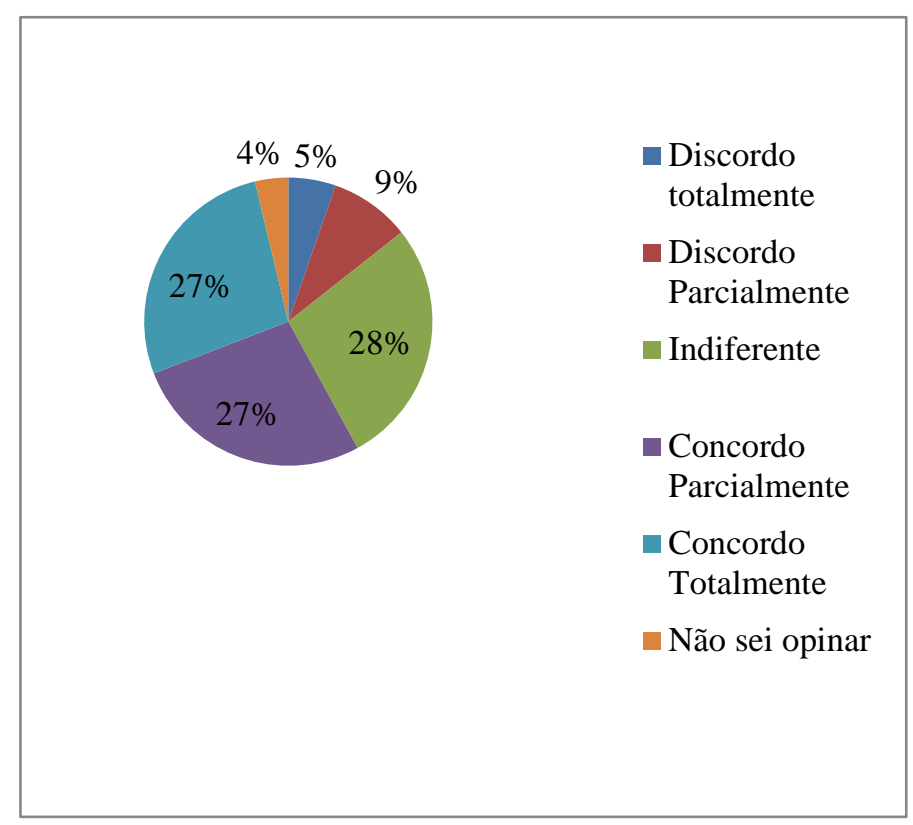

Fonte: Dados da pesquisa, 2018.

Especificamente no caso em questão, foi verificado se os produtos faziam parte da motivação principal de viagem, o gráfico 03 expõe esse resultado. 
Gráfico 1: Opinião quanto à motivação principal da viagem relacionada aos pleiteantes de IG

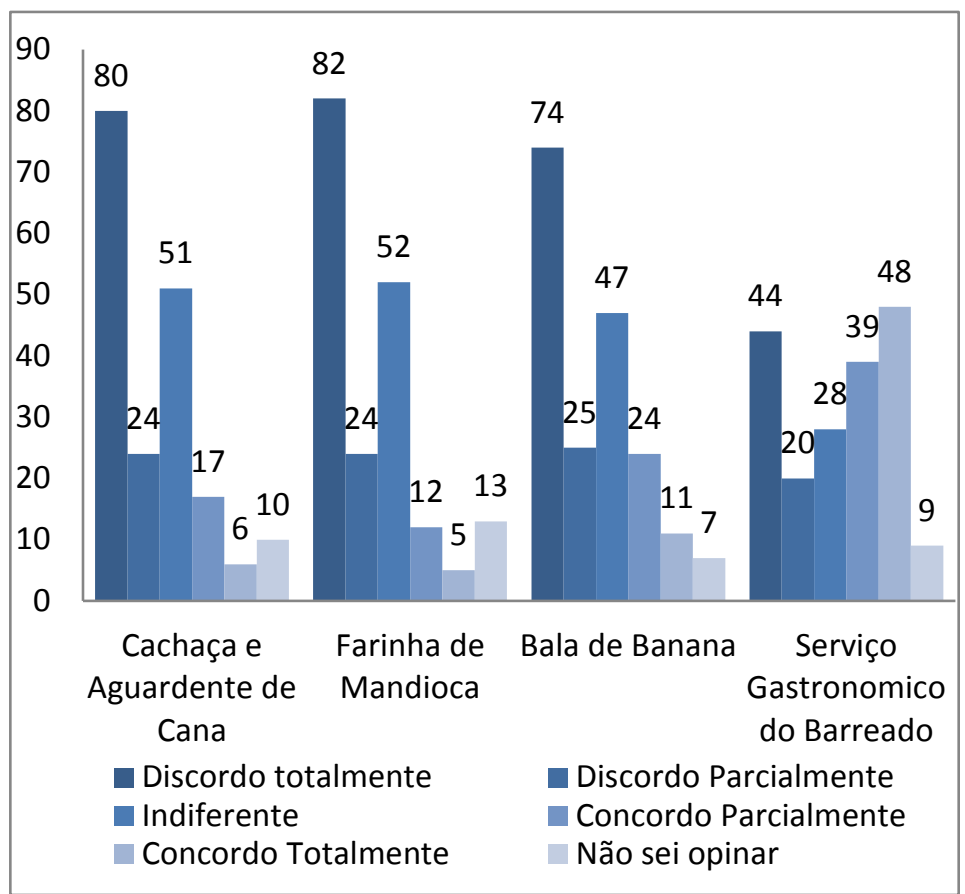

Fonte: Dados da pesquisa, 2018.

Pode se perceber que o serviço gastronômico do barreado foi a principal motivação de viagem para $48 \%$ dos respondentes para este serviço. Os demais produtos expostos ao turista não foram a principal motivação da viagem (cachaça e aguardente de cana, farinha de mandioca e bala de banana), ou seja, os respondentes não se deslocaram de sua cidade de origem com a motivação principal de consumo/compra destes.

Com relação aos produtos/serviço com elevado número de respondentes em discordância total, pode se observar que houve um grande número de respostas na categoria "indiferente". Esse fato aponta que há possibilidade de inserção de novas atividades (como oficinas, festivais, entre outros já mencionados) com foco principal nesses e isso pode vir a influenciar a motivação. Essa questão necessitaria maior aprofundamento investigativo, mas a atitude favorável dos respondentes com relação à realização das atividades corrobora para tal apontamento. Assim, entende-se que há diversas possibilidades de valorização e utilização turística dos produtos gastronômicos, em especial aqueles com pleito de IG, no Litoral do Paraná.

\section{Considerações Finais}

Para alcançar o objetivo geral de analisar o consumo e as atitudes dos turistas com relação aos produtos gastronômicos do litoral Paranaense, o presente trabalho utilizou apesquisa documental em bases de dados online e análise das opiniões dos turistas por meio de questionários aplicados online. Esse instrumento contemplou uma primeira parte contemplando o consumo de diversos produtos do litoral e depois enfocou o consumo e atitude relacionados especificamente aos produtos que podem tornar-se indicações geográficas reconhecidas.

A região apresenta quatro processos pleiteantes de indicação geográfica, sendo 03 produtos e um serviço: cachaça (produto), farinha de mandioca (produto), bala de banana (produto), e barreado (serviço). Durante as pesquisas foi perceptível o consumo e interesse dos turistas com relação a atividades turísticas relacionadas aos produtos estudados, comprovando assim a possibilidade de interseção entre IGs e turismo.

A região possui potencial turístico cultural e gastronômico parcialmente desenvolvido atrelado a indicação geográfica, pois já há algumas atividades como eventos e informação em local de produção que destacam os processos em andamento. Com base nos interesses dos respondentes analisados neste trabalho aliado a referencias como Fagliari (2005), Medeiros e Passador (2015), Gimenes-Minasse (2015) com relação a atividades gastronômicas, mencionadas no referencial bibliográfico, outras atividades são apontadas. Estas atividades podem ser analisadas e agregadas a fim de fomentar a oferta turística do litoral paranaense, tendo como um diferencial relacionado à unicidade decorrente da indicação geográfica.

Dentre as atividades estão: a participação ou criação de eventos (harmonização com outros produtos, eleição de melhores produtos, seminários, etc.; fomento dos locais de produção com atividades como lojas, restaurantes e hotelaria; criação de uma rota gastronômica; criação de um museu; criação de livro de receita das IGs e uso do trem turístico Serra Verde Express. As atividades listadas podem ser concomitantes e inseridas em diferentes momentos, 
envolvendo produtos, produtores, chefs, indústrias, mercados, atividades culturais, turistas, meios de transporte (trem), entre outros. Os apontamentos realizados neste trabalho devem ser moldados de acordo com a realidade da região e os municípios que a abrange.

A pesquisa tem contribuições acadêmicas por enfocar um tema ainda pouco explorado dentro do campo do turismo. Também possui claras implicações mercadológicas ao destacar aspectos do comportamento do consumidor e oportunidades de negócios. Entretanto, o trabalho não esgota o assunto, mas sim suscita uma grande gama de outras investigações. Assim, sugere-se como estudos futuros analisar os souvenires da região litorânea e seu uso turístico; quanto à viabilidade de implantação de uma rota gastronômica englobando as áreas de abrangência de IG pelos diferentes municípios e produtores da região; e evento com foco exclusivo em indicações geográficas aliado ao turismo gastronômico e cultural na região litorânea do Paraná.

\section{Referências}

1 ADETUR. ADETUR Litoral: Agência de Desenvolvimento do Turismo Sustentável do Litoral do Paraná. Disponível em: $<$ http://www.adeturlitoral.com.br/quemsomos.php >. Acesso em: 05 set. 2017.

2 ALTINTZOGLOU, T.; HEIDE, M.; BORCH, T. Food souvenirs: buying behaviour of tourists in Norway. British Food Journal, v. 118, n. 1, p. 119131, 2016.

3 BALTAR, F.; BRUNET, I. Social research 2.0: virtual snowball sampling method using Facebook. Qualitative Research Journal, Reino Unido, v. 22, n. 1, p.47-74, ago. 2011.

4 BARDIN, L. Análise de conteúdo. Lisboa Portugal: Edições 70, 1977.

5 BRASIL. Ministério do Turismo. Turismo Cultural: Orientações Básicas. 3. ed. Brasilia: Ministério do Turismo, 2010.

6 BRICKMAN-BHUTTA, C. B. Not by the Book: Facebook as a Sampling Frame. Sociological Methods \& Research, Publicação Online, v. 41, n. 1, p.57-88, mar. 2012.

7 CERDAN, C. Indicações Geográficas e estratégias de desenvolvimento territorial. In: NIEDERLE, Paulo André. Indicações

Geográficas: Qualidade e origem nos mercados alimentares. Porto Alegre: UFRGS, 2013. p. 125150.

8
FAGLIARI,
G.
S. Turismo
e
Alimentação: Analises Introdutória. São Paulo: Roca, 2005.

RANZONI, E. A gastronomia como elemento cultural, símbolo de identidade e meio de integração. [s.I.] Universidade Nova de Lisboa, 2016.

10 GÂNDARA, J.M.G. et al. Reflexões sobre o turismo gastronômico na perspectiva da sociedade dos sonhos. In: PANOSSO NETO, A.; ANSRAH, M. G. R. Segmentação do mercado turístico: estudos, produtos e perspectivas. Barueri, São Paulo: Manole, 2009.

11 GIL, A. C. Métodos e Técnicas de Pesquisa Social. 6. ed. São Paulo: Atlas, 2008.

12 GIMENES-MINASSE, M. H. S. G. Para Turista Ver (E Provar): dos usos do patrimônio gastronômico no contexto do turismo. Tessituras, v. 3, n. 2, p. 175-194, 2015.

13 GOELDNER, C. R. et al. Tourism: Principles, Practices, Philosophies. 8th Ed. New York: John Wiley and Sons, 2000.

14 HENDERSON, J. C. Food tourism reviewed. British Food Journal, v. 111, n.4, p.317-326, jan. 2009.

15 HORODYSKI, G. S.; MANOSSO, F. C.; GÂNDARA, J. M. Conceitos e Abrangência do Souvenir na Dinâmica do Espaço Turístico: O Caso de Curitiba-PR. Turismo, Visão e Ação, Eletrônica, v. 15, n. 1, p.130-143, abr. 2013.

16 INPI. Guia básico de indicação geográfica. 2018. Disponível em: <http://www.inpi.gov.br/menuservicos/indicacao-geografica>. Acesso em: 25 jul. 2018.

17 INPI. Pedidos de indicação geográfica concedidos e em andamento: Andamento dos pedidos. 2018. Disponível em: <http://www.inpi.gov.br/menu-servicos/indicacaogeografica/pedidos-de-indicacao-geografica-nobrasil>. Acesso em: 14 out. 2018.

18 KARIM, S. Ab; CHI, C. G. Culinary Tourism as a Destination Attraction: Na Empirical Examination of Destinations' Food Image. Journal Of Hospitality Marketing \& Management, v. 6, n. 19, p.531-555, jul. 2010.

KIVELA, J.; CROTTS, J. C. Tourism and Gastronomy: Gastronomy's Influence on How Tourists Experience a Destination. Journal of Hospitality \& Tourism Research, v. 30, n. 3, p. 354-377, 1 ago. 2006. 
20 KOVALESKI, A. A Oferta de Souvenirs Gastronômicos no Destino Morretes/PR. 2018. 155 f. Dissertação (Mestrado) - Curso de Turismo, Universidade Federal do Paraná., Curitiba, 2018.

LIMA, C. Tachos e Panelas: historiografia da alimentação brasileira. 2. Ed. Recife: Editora do Autor, 1999.

LIN, Y.; PEARSON, T. E.; CAI, L. A. Food as a form of destination identity: a tourism destination brand perspective. Tourism and Hospitality Research, v. 11, n. 1, p. 30-48, 2011.

MEDEIROS, M. de L.; PASSADOR, J. L. Indicações Geográficas E Turismo: Possibilidades no Contexto Brasileiro. Perspectivas Contemporâneas: Revista Eletrônica de Ciências Sociais Aplicadas, v. 10, n. 3, p.56-79, dez/2015.

MENDES, P.P.M.; ANTONIAZZI, L. O uso das Indicações Geográficas como instrumento de proteção e desenvolvimento da agricultura brasileira. In: PLAZA, C.M.C.A. et al. (Eds.). Propriedade Intelectual na Agricultura. Belo Horizonte: Fórum, 2012. p. 343-366.

NUNES, G. S.; BANDEIRA, M. G. A.; NASCIMENTO, J. S. Indicações Geográficas (Igs): Instrumento De Desenvolvimento Sustentável. Geintec, São Cristóvão, v. 2, n. 4, p.344-352, ago. 2012.

OLIVEIRA, A. C. R. M. de; OLIVEIRA, S. Indicação Geográfica dos Doces de Pelotas: Uma Reflexão Turística Acerca da Certificação. In: SEMINTUR JR., 4 Edição, 2013, Porto Alegre. Anais. Porto Alegre: UCS, 2013. p. 1 - 15. Disponível em: <https://www.ucs.br/site/midia/arquivos/indicacao _geografica.pdf>. Acesso em: 22 ago. 2018.

PELLIN, V.; CURADI, F. C. Potencialidades e limites das indicações geográficas (IGs) como estratégia de desenvolvimento territorial sustentável em Santa Catarina. RMGC -Revista Metropolitana de Governança Corporativa, São Paulo, v. 3, n. 2, p.03-18, jul/dez. 2018.

QUAN, S.; WANG, N. Owards a structural model of the tourist experience: an illustration from food experiences in tourism. Tourism Management, v. 25, n. 3, p.297-305, mai. 2004.

RIBEIRO-MARTINS, C. de S.; SILVEIRAMARTINS, E. Turismo Gastronômico: Uma Pesquisa Bibliométrica Em Bases De Dados Nacionais E Internacionais. Turismo Visão e Ação, v. 20, n. 1, p.184-208, jan/abr. 2018.

30 Secretaria do Esporte e Turismo - Regiões Turísticas. Disponível em: http://www.turismo.pr.gov.br/modules/conteudo/c onteudo. php?conteudo=247? \&mobile=0. Acesso em: 16/02/2017 às 11h: 13min.

31 SEBRAE. Indicações Geográficas do Paraná. Disponível em: <https://sgcwem.pr.sebrae.com.br/PortalSebrae/ sebraeaz/Indicacao-geografica>. Acesso em: 10 set. 2017.

32 SHARPLES, L. The world of cookery-school holidays. In: HALL, C.M. et al. (orgs.). Food Tourism around the World: development, management and markets. Oxford: ButterworthHeinemann, 2003.

33 STONE, M. J.; MIGACZ, S.; WOLF, E. Beyond the journey: the lasting impact of culinary tourism activities. Current Issues In Tourism. Online. jan. 2018.

34 TONINI, H. Vinhos , Turismo e Pluriatividade na Agricultura. Rosa dos Ventos, v. 5, n. 2, p. 218227, 2013.

VARELLA, M.D.; BARROS, A. F. G. Indicações Geográficas e Arranjos Produtivos Locais. In: VARELLA, M. D (Ed.). Propriedade Intelectual e Desenvolvimento. São Paulo: Lex Editora, 2005. p. $361-358$ 